\title{
EL TÍTULO DE CRÉDITO HIPOTECARIO NEGOCIABLE
}

\author{
Manuel Sánchez-Palacios Paiva*
}

\begin{abstract}
Resumen:
El artículo se inicia con los antecedentes legislativos, del ahora desaparecido Sistema de A horro y Crédito para Vivienda, formado por las Mutuales de Vivienda y su organismo central el Banco de la Vivienda, luego trata la naturaleza de la hipoteca en nuestra legislación y su carácter accesorio, sigue con la hipoteca independiente del Derecho Germano, cuya naturaleza examina y entrando en materia desarrolla el concepto del Título Hipotecario Negociable y su Mercado.
\end{abstract}

Palabras clave: Sistema de crédito - Crédito Hipotecario - Negociable Hipoteca - El Mercado.

A bstract:

The article begins with the legislative antecedents of the disappeared System of Saving and Mortgage Loans, formed by the «M utuales de Vivienda» and its central organism «Banco de la Vivienda». Further explains the nature of the mortgage in our legislation and its accessory character, followed by the independent mortgage of the Germanic Law, whose nature examines, and develops the concept of the Negotiable mortgage and its market.

Key words: Credit System - Mortgage Loan - Negotiable - Mortgage - The Market

\section{Sumario:}

1. Introducción. 2. La Hipoteca. 3. La Hipoteca independiente del derecho germano. 4. El Título de crédito hipotecario negociable. 5. El Mercado.

* Vocal Titular de la Corte Suprema de Justicia dela República del Perú. Presidente de la Sala de Derecho Constitucional y Social. 


\section{INTRODUCCIÓN}

Antecedentes:

El sistema decrédito hipotecario privado queformaron las mutuales devivienda, regidas por la Ley 12813, inspiradas en las asociaciones de ahorro y préstamo existentes en los Estados Unidos deA mérica y en las sociedades deconstrucción inglesas (building societies), planteó la creación denuevas formas decontratos de hipotecas que permitieran formar un Mercado Secundario de Hipotecas. Es que el otorgamiento de créditos a plazo de hasta veinte años, con recursos provenientes en su mayoría de depósitos de ahorro a la vista, presentaba un manejo financiero de difícil coyuntura, que la existencia de un Mercado de Hipotecas tal vez hubiera solucionado.

Por esa razón, entonces, se planteó la necesi dad de autorizar nuevas formas de crédito hipotecario que permitieran la creación de un Mercado Secundario de Hipotecas.

En ese tiempo el Código Civil de 1936 regulaba la hipoteca voluntaria y la hipoteca legal, y en el tratamiento de la primera incluyó a la hipoteca para garantizar títulos transmisibles por endoso o al portador, conocida como de "cédulas", y luego en el Libro de los Contratos regulaba de manera prolija con el título de "Obligaciones Provenientes de la Voluntad Unilateral", la emisión delos bonos hipotecarios, (artículo 1802 y siguientes) lo querequería la necesaria intervención del entonces Banco Central Hipotecario, en calidad de fideicomisario, con el encargo deverificar la regularidad legal dela emisión, la suficiencia económica de la garantía, y representar a los actuales y futuros poseedores de los títulos.

El Banco Central Hipotecario, creado por la Ley № 6126 emitió papeles a los que denominó Cédulas y queen real idad eran bonos quetenían baselegal en su propia ley y no se respal daban con una hipoteca específica, sino con la cartera hipotecaria global que tenía dicho Banco, su colocación era forzada, pues los préstamos comunes que otorgaba dicho Banco se desembolsaban una parteen esos títulos que el prestatario debía negociar en el Mercado para hacerlos efectivas. Es cierto quetambién podía pagar una partedesu deuda con papeles iguales, los que podía adquirir en el Mercado. Tanto la venta como la comprase cotizaba por debajo del valor nominal. 
Antes de esto, la Ley de Bancos Hipotecarios de fecha 2 de Enero de 1889 autorizó el otorgamiento depréstamos con garantía hipotecaria para amortizarse en un plazo dehasta treinta años, y facultó la emisión de cédulas hi potecarias. En 1896 se otorgó igual facultad a la Caja de Ahorros de la Sociedad de Beneficencia, y posteriormente, al promulgarseel Código deComercio sereguló los Bancos de Crédito territorial, a los que se otorgó las mismas facultades ${ }^{24}$.

El Código Civil de 1984, contra lo esperado, simplificó la norma relativa a la hi poteca de cédulas y omitió toda regulación referente a la emisión de los bonos hipotecarios. Tal vez pesó en el ánimo del legislador el hecho de la no utilización delas normas que esa materia incluyó el Código Civil de 1936, que derogó.

Desde entonces pasaron algunos años para que se llenara ese vacío legal. Primero la Ley de Mercado de Valores, Decreto Legislativo N o 861 de fecha 22 de octubre de 1996, que autorizó la inscripción de un valor o un programa de emisión de valores en la CONASEV. Después la Ley General del Sistema Financiero № 26702, de fecha 9 de diciembre de ese mismo año, que en sus artícul os $232^{\circ}$ al $240^{\circ}$ regula la emisión deinstrumentos financieros decaptación de ahorro del público, emisión de bonos, letras hipotecarias y cédulas hipotecarias, y la nueva Ley de Títulos Valores № 27287 que les reconoce el carácter deTítulo Valor, con todas las consecuencias jurídicas queello produce.

\section{LA HIPOTECA}

1. Antecedente histórico. 2. Características. 3. Clasificación. 4. Bienes hipotecables.

1. El genio jurídico romano plasmó el concepto de la Propiedad como un derecho real que vincula una cosa con una persona, quien goza de los atributos clásicos que aún se le reconocen, y del que se derivan como desmembraciones todos los otros derechos reales, y atendiendo a las necesidades derivadas del incremento de las relaciones de crédito y del comercio, ideó una forma degarantizar obligaciones personales afectando a ese propósito un inmueble con la característica especial que, a diferencia dela prenda, no significaba para el propietario la pérdida de su posesión, disfrute y nuevo gravamen, y al mismo tiempo otorgaba al acreedor un derecho real quelo vinculaba directamentecon el bien gravado y leotorgaba la facultaba devenderlo en el caso queel deudor no pagarála obligación. ${ }^{25}$ 
Estees el concepto dela hipoteca quebásicamentesemantieneen los sistemas jurídicos correspondientes a la Tradición Romana, con la diferencia y agregado dela inscripción en el Registro Público, queel romano no conoció.

Modernamente la hipoteca se puede definir como "derecho real registral de garantía concreta, en cosa inmueble determinada, cuya posesión conserva el propietario y que faculta al titular a exigir, si no secumplela obligación garantizada, la venta pública de aquella, resarciéndose con su precio. ${ }^{26}$

\section{Sus características son:}

a. Es un derecho real, pues se establece un vínculo entre el acreedor y el inmueble hipotecado, con prescindencia desu propietario.

b. Es un derecho registral, porquesolo nace cuando seinscribe. La inscripción es en estecaso constitutiva, a diferencia del carácter puramentedeclarativo que la inscripción tiene para otros derechos. Messineo, citado en la Exposición de Motivos Oficial del artículo 19880 del Código Civil señala; "la hipoteca se constituye únicamente cuando él que está provisto del título procedea inscribirlo en el registro hipotecario; el contrato es necesario pero no suficiente para hacer surgir la hipoteca. ${ }^{27}$

c. Es de garantía concreta, porque respalda una obligación determinada o determinable, y el gravamen debe establecerse también por cantidad determinada o determinable. El artículo 10999 del Código Civil establece sus requisitos. ${ }^{28}$

d. Y, siempresedijo quees accesoria. A hora hay quedecir, quees normalmente accesoria, pues garantiza el cumplimiento de obligaciones, para cuya seguridad se constituye. La incorporación de la auto hipoteca en nuestra legislación, que tiene un carácter de independencia constituye una excepción a esta regla. Es también una excepción la hipoteca para garantizar obligaciones futuras o eventuales prevista en el artículo 1104º del Código Civil.

2.1. Desdeun punto devista registral, la hipoteca presenta las siguientes notas:

Es inseparable de la cosa gravada, pues sujeta directa einmediatamenteel bien sobre el que recae, aún cuando cambie de propietario; es indivisible, pues se 
extiende a todas las partes integrantes del bien hipotecado y a sus accesorios, subsiste íntegra sobre el bien o bienes hipotecados mientras no sea cancelada aunque se reduzca el monto de la obligación, o sobre la parte que quede si se ha destruido, y sobre el monto de las indemnizaciones de los seguros si los hubiere y la expropiación.

Esta regla recogidaen el artículo 1101ㅇdel Código Civil debeconcordarsecon los artículos $887^{\circ}$ y $888^{\circ}$ del mismo Código que definen como "integrante" lo que no puede ser separado sin destruir, deteriorar o alterar el bien, y como "accesorios" los que, sin perder su individualidad, están afectados a un fin económico u ornamental con respecto al bien; lo quequiere decir quelo queseagregueal bien, en cualquiera de estas dos condiciones, también queda hipotecado.

Es pública, lo que resulta de su necesaria inscripción en el Registro Público;

Es Especial izada, tanto en cuanto a los bienes afectados, como a las cantidades por la que estos responden. (artículos 1100 y 10999inciso 3 del Código Civil.)

\section{Clasificación de hipotecas}

Antiguamente se reconocían las hipotecas legales, voluntarias, judiciales, generales, especiales, expresas, tácitas, ordinarias, privilegiadas y hasta testamentarias.

Hoy legalmentese reconocen las siguientes:

a. Desde el punto de vista de su constitución: Voluntarias y legales. Las primeras son las que se contratan libremente; las segundas resultan por ministerio dela ley, con ciertos requisitos, como por ejemplo ladel inmueble enajenado sin quesu precio haya sido pagado totalmente, (artículo 1118응 del Código Civil.)

b. Desdeel punto de vista de su naturaleza: Ordinarias y excepcionales. Las primeras son las que responden a las características ya señaladas del sistema romano del derecho, que se constituyen como accesorias para garantizar el cumplimiento de una obligación principal, en favor de un acreedor determinado, por cantidad precisa sin duración limitada, y transmisible por un instrumento igual al de su constitución. Entre las segundas se cuenta la auto hipoteca y la hipoteca en garantía de títulos 
transmisibles por endoso o al portador, en las queel acreedor no se determina y tampoco el monto garantizado y sólo tienen un límite máximo.

\section{Bienes hipotecables}

El principio jurídico es que se puede hipotecar lo que se pueden vender, y aunque esta regla contenida en el artículo $1010^{\circ}$ del Código Civil de 1936, que fue el primer artículo con que comenzaba el Título de la hipoteca voluntaria, no ha sido recogida como tal en el Código Civil vigente, es dela naturaleza de la hi poteca, pues ésta confiere al acreedor la facultad de hacer vender la cosa. Si el bien no sepuedevender, el derecho real dehipoteca resultaría irrealizable. Tienen que ser bienes que se encuentren en el comercio de los hombres. Un bien inembargable no se puede hipotecar, como por ejemplo los bienes sobre los cuales se ha constituido Patrimonio Familiar conforme al artículo $488^{\circ}$ y siguientes del Código Civil.

\section{Sepueden hipotecar:}

Los inmuebles inscritos o susceptibles de inscripción. El artículo 8850 del Código Civil enumera cuales son bienes inmuebles; pero sólo se pueden hi potecar, aquel los inscritos o inscribibles. A sí, l os predios rústicos o urbanos, las minas, las naves y aeronaves, los diques y muel les, los edificios flotantes y pontones, los ferrocarriles, etc. La legislación anterior concedía una salida para la hipoteca de los inmuebles no inscritos, que se llamaba la "protesta de hipoteca", que se anotaba en el Registro de la Propiedad Inmueble conforme al artículo 1042 inciso 6 del Código derogado. Esta promesa de hipoteca no ha sido legislada.

Los derechos sobre inmuebles inscribibles en el Registro. Y aquí se abre un gran abanico donde se ubican el Usufructo convencional, el Uso, el derecho deHabitación, y el derecho de Superficie, los que una vez constituidos Ilevan a un desdoblamiento de la propiedad en dominio útil y dominio directo, también llamada "nuda" propiedad por quedar esta desprovista de sus atributos. La hipoteca que se constituya no podrá tener un plazo mayor al establecido para la vigencia de esos derechos.

La nuda propiedad, que se circunscribe al dominio directo, también puede hipotecarse y surgirá una cuestión controvertible si en al gún momento la propiedad se consolida en la persona del titular de la nuda propiedad. En ese 
caso algunos sostienen que la hipoteca se debería extender al derecho incorporado, pues el dominio reposa en la nuda propiedad y no sobre las meras desmembraciones de éste, y admitir lo contrario importaría afirmar la subsistencia de la desmembración extinguida. Mas esa teoría no supera la situación que se produce cuando la propiedad se consolida en el titular del dominio útil, caso en el cual la hipoteca sól o subsistirá sobrela nuda propiedad. Para ambos casos lo mejor será un pacto previo.

Las explotaciones económicas, como autoriza el artículo 1103del Código Civil.

Son también posibles las hipotecas sujetas a condición o a plazo (artículo 1105 ㅇel Código Civil) así, se podrá hipotecar un bien vendido con pacto de retroventa, o cuando se estableció la facultad de un retracto convencional, en cuyo caso el hecho futuro e incierto que configura la condición está dado por la efectividad de esos derechos; o la hipoteca sobre bienes sujetos a un litigio.

En la práctica diaria sucede que una hipoteca se constituye para asegurar el cumplimiento de obligaciones personales, de tal manera que si se ejecuta la garantía y su valor de venta no cubre la deuda, el acreedor siempre tendrá la acción personal contra su deudor por el saldo no cubierto. ${ }^{29}$

Hasta aquí tenemos el tema general de las hipotecas desde el punto de vista de la vertiente romana del Derecho.

Es oportuno anotar que, como consta en la Exposición de M otivos Oficial del Código Civil, el doctor Guillermo Vel aochaga propuso incorporar la Hipoteca de responsabilidad limitada, tomando como antecedenteel artículo $140^{\circ}$ dela Ley Hipotecaria Española, pero la mayoría consideró que esa limitación correspondía a un pacto privado, por lo que no fue incorporada..$^{30}$

\section{LA HIPOTECA INDEPENDIENTE DEL DERECHO GERMANO}

1. A ntecedente histórico. 2. Antecedente legislativo. 3.Concepto germano de la inscripción registral. 4. Características. 5. Variedades.

1. Roma impuso para sus súbditos el principio de la personalidad de la ley, y los romanos se regían por la ley de Roma, independientemente del lugar dondeseencontraran; por eso San Pablo, por ser romano, fuejuzgado por su 
ley personal. Después de la caída del Imperio Romano de Occidentesiguió rigiendo ésteprincipio y así, a cada cual le aplicaban la ley desu pueblo, con los inconvenientes queesto producía en los lugares de población mixta.

Esto significó queel Derecho Romano, impuesto por las legionesimperiales, subsistiera para los romanos aún después dela caída del Imperio Romano de Occidente, al punto que los mismos reyes bárbaros auspiciaron las compilaciones de las leyes romanas.

El Derecho Romano tuvo sobrelos Derechos de otros puebl os la ventaja de ser escrito y, en su contacto con los pueblos germanos, impuso muchas de sus instituciones, como el derecho de propiedad y la forma de trasmitirlo.

Como se recordará la compra venta romana no trasmitía la propiedad, era necesario que a continuación de ésta se produjera la tradición. Esto dio origen a la "teoría del título y el modo" que aún hoy perdura en nuestro sistema, pues en la compraventa según el artículo 15290 del Código Civil el vendedor sólo se obliga a transferir la propiedad del bien al comprador, y si no fuera por la existencia del artículo 949 del mismo Código, no se produciría la transferencia efectiva.

Es sólo a partir del Siglo XIII cuando el principio de la personalidad de la ley se debilita frenteal principio dela territorialidad.

La propiedad, si bien es reconocida como el derecho más amplio que se puede tener sobre una cosa, es transmitía al igual que en el Derecho Romano, por el negocio de enajenación, sea compraventa, donación, etc. (título) seguido por la tradición del inmueble (modo), que entre los germanos se llamaba "investidura" en referencia a la posesión, lo que se realizaba físicamente en el predio. Esto fue evolucionando, reemplazándose la tradición física por la entrega de un objeto simbólico como un terrón, una rama, un postedel cerco, o un objeto queserelacionaba con el señorío sobreel bien, como un bastón o un guante, luego se aceptó una investidura procesal mediante un procedimiento judicial con allanamiento, y final mentesesuscribía un documento ${ }^{31}$ que representaba la investidura incorporal.

Desdeel altaEdad Media segeneralizó la costumbredeasegurar mediante una nota escrita los negocios relativos a inmuebles, y los grandes 
terratenientes empleaban libros en donde copiaban los documentos referentes a sus propiedades.

Es posible que estos libros privados sirvieran de modelo a los Libros Públicos que se llevaban en los Municipios, en los que comenzaron a consignarse las enajenaciones de inmuebles.

El instituto de "Los Libros Registrales" tuvo un desarrollo paulatino: de los libros generales se pasó a libros para cada ti po denegocios, y luego dentro de estos sellegó a establecer un lugar especial para un mismo inmueble, ${ }^{32}$ dando lugar a las Ilamadas Partidas Registrales, germen de los modernos Registros Públicos, y finalmentesellegó a establecer quela transmisión de la propiedad se producía por el acuerdo, o sea el negocio jurídico, y su inscripción en el Libro.

De allí siguió que una cosa podía darse en prenda por una deuda de manera quesólo responda la cosa sin responsabilidad personal del deudor, y que el acreedor, anteel incumplimiento del deudor, tenía el derecho de vender el bien gravado ante el tribunal o el concejo municipal, y que, al igual que la transmisión de la propiedad, el gravamen se constituía con su registro en los libros.

2. El antecedente más próximo se encuentra en las hipotecas independientes del derecho germano (Grudschuld) y la del propietario (Eigentümerhypothek).

Tiene su origen en Alemania, en el Estado de Mecklemburgo, después la adoptó la Ley de Hipotecas y de Organización del Registro de Prusia de fecha 5 de mayo de 1872 y fuerecogida en el B.G.B. (Código Civil Alemán) que en su artículo $1191^{\circ}$ la define como "gravamen consistente en pagar una determinada suma de dinero a la persona favorecida con él, sobre el inmueble". Wolff la define como "El gravamen no accesorio de un inmueble, con una suma de dinero cobrable sobre el mismo". 33

La hipoteca independiente es también llamada "deuda territorial", o de "inversión capitalista"

3. En el Derecho Germano la inscripción en el Registro Público tienecarácter constitutivo, detal manera queed sólo negocio jurídico relativo a un derecho real no surte efecto mientras no se inscriba, y es sólo con esta que cobra vigencia. 
Entrenosotros la inscripción en el Registro es meramentedeclarativa, cumple una función de publicidad frente a terceros, se inscriben los acuerdos ya consumados para la constitución, modificación o extinción de derechos, no es un requisito de la adquisición, modificación o extinción del derecho real; sal vo el caso de la hipoteca.

Hay una iniciativa legislativa procedente de la Comisión de Reforma del Código Civil que presidió el doctor Jorge Muñiz, para modificar el actual sistema detransmisión de la propiedad y reemplazarlo por uno constitutivo a partir de la inscripción en el Registro Público.

El Derecho Germano alcanzó en su evolución ésta característica, desde hace muchos años, con gran ventaja para la seguridad de las operaciones de tráfico inmobiliario. El requisito y supuesto básico de este sistema es contar con un Registro Público degran eficiencia.

\section{Características}

Es independientey abstracta

\section{a. Independencia}

La hipoteca, entrenosotros, siempreseconcibió como un derecho real accesorio de otro derecho, general mente de crédito, de acuerdo con nuestra ideología romano histórica.

Esta es una hipoteca distinta. Naceindependiente, puesto que no es accesoria de otra obligación, y no hay deudor. Estamos acostumbrados a que el propietario de un bien asuma una obligación personal y para garantizar su cumplimiento constituye hipoteca sobre un bien de su propiedad. La obligación puede ser propia o ajena. En caso deincumplimiento el acreedor, como autoriza el artículo $1117^{\circ}$ del Código Civil, puedeexigir el pago al deudor por la acción personal o iniciar la acción hipotecaria contra el propietario de la cosa, aún cuando sea un tercero, en el proceso de ejecución de garantías conformeal artículo $720^{\circ}$ del Código Procesal Civil; ejercitada la acción real, si el remate del bien no cubre la deuda, el acreedor tiene todavía una acción personal para cobrar su acreencia como establece el artículo 724이 del Código Adjetivo. 
En la hipoteca independiente, el deudor es para la eficiencia del crédito el inmueble mismo, y el acreedor será el tenedor del Título representativo de la hipoteca, quepuedeser cual quier persona quelo haya adquirido de una manera legítima. Incluso es el propietario del bien, antes deceder el Título o después de pagada la obligación garantida.

De acuerdo con esta distinta concepción, la hipoteca ya no es el mero instrumento de garantía de una obligación personal preexistente o coetánea, sino un medio de usar el crédito directamente sobre los inmuebles. A sí esta hipoteca no se cancela cuando se paga al acreedor, sino que el Título que la representa, que es un valor negociable, puede ser entregado a un nuevo acreedor, a cambio del val or querepresenta. Mientras la hipoteca no secancele en el Registro puede seguir utilizándose.

Por las mismas razones, esta hipoteca no se extingue por la caducidad o extinción dela obligación garantizada, ni leafectan los vicios de nulidad de la misma; lo mismo entre las partes que en cuanto a terceros.

En la concepción original germana y hasta la contenida en la Ley Española de 1944, en esta hipoteca el deudor sólo responde con la finca. Por eso es deuda del fundo (Grundschuld). Por eso se dicequeno es deudor el propietario sino el inmueble, y nada más que é.

\section{b. Es abstracta}

Es abstracta por su independencia detoda causa. Toda operación patrimonial se funda en una finalidad jurídica, (la causa) que por lo general establecen las partes. Un acto jurídico de efecto patrimonial será causal cuando el acuerdo sobrela causa integra el acto, o sea que seexpresecomo razón motivantedeéste.

General mente, el acuerdo sobrela causa seconsidera como un elemento queno entra en el acto jurídico dela atribución patrimonial y permaneceinterno. Para la validez del contrato no se exigemás queel acuerdo de las partes respecto de la modificación jurídica que seproponen realizar. Cuando en esas atribuciones se prescinde de la causa, se les suele denominar abstractas. ${ }^{34}$

En la doctrina alemana, por lo general todo contrato deefecto real es abstracto. La constitución deuna hipoteca por acto unilateral esabstracta, pues carece de causa. ${ }^{35}$ 


\section{Variedades}

A demás dela hipoteca decédula, la legislación germana aceptó otra modalidad conocida como la hipoteca a favor del propietario.

Esta hipoteca se inscribe inicial mentea favor del dueño de la cosa hipotecada.

Partiendo del principio que es posible constituir una hipoteca independiente, que no presupone la existencia de un derecho de crédito a favor de persona distinta del propietario de la cosa gravada, es forzoso concluir queesa hi poteca tiene como único titular de disposición al referido dueño.

Esta idea pugna también con nuestra ideología romana. Es mas, para nosotros vendría a ser un contrasentido, pues nadie es deudor ni acreedor desí mi smo, pues tales obligaciones se extinguen por consolidación. La consolidación es una forma de extinción de las obligaciones, como seestableceel artículo $1300^{\circ}$ del Código Civil. Porquesi el dominio importa todoslos derechos imaginables que puedan existir sobre la cosa, no puede hablarse de un "dueño" que con titularidad jurídica independientesea beneficiario dehipoteca sobre su propia cosa; como no podría serlo de una servidumbre o del usufructo.

Aquí el propietario puede constituir hipotecas de distinto rango, también independientes, con la especial característica de que las segundas no modifican su rango, cuando se cancela la primera. No obtienen una mejora de puesto como en los sistemas hipotecarios de la vertiente romana. En el fondo se trata de una reserva del rango de la hipoteca.

Tiene la ventaja para el propietario de que al cancelarse la primera hipoteca deja un puesto libre devalor, a disposición del dueño, que puedenuevamente ser negociado; lo que no perjudica a los segundos acreedores, quienes negociaron su crédito sobrela base del valor residual del inmueble, por lo que mantienen su rango o puesto inicial.

\section{EL TÍTULO DECRÉDITO HIPOTECARIO NEGOCIABLE}

1. Definición. 2. Requisitos de la escritura pública. 3. Rango de la hipoteca. 4. Requisitos del Título. 5. Circulación. 6. Ejecución. 7. La venta directa. 8. Cancelación dela hipoteca. 9. Laacción residual. 10. Casos deabuso.11. Pérdida del Título. 12. Retorno dela hipoteca al propietario del inmueble. 13. Normas supletorias. 14. N aturaleza de la hipoteca. 
1. La ley General del Sistema Financiero №26702 de Diciembre de 1996 trajo una novedad. En su artículo $239^{\circ}$ introdujo el "Título de Crédito Hipotecario Negociable", que es definido como: un título valor a la orden y negociable por endoso, emitido por el Registro Público donde se encuentreinscrito el inmueble que se grave con hipoteca, en mérito al otorgamiento de una escritura pública en la que por acto unilateral se constituye el gravamen hipotecario de primer rango quesirvedegarantía al crédito consignado en el mismo, con preferencia a toda otra acreencia, cual quiera sea su origen o naturaleza".

El Reglamento delaley, dictado por la Superintendencia de Banca y Seguros mediante Resolución № 838-97 de 30 de Noviembre de 1997 agregó: El título deCrédito Hipotecario Negociableemitido por el Registrador Público es un Título Valor querepresenta el derecho real dehipoteca sobre un bien inmueble, y puede ser endosado libremente a favor de cualquier persona sólo en garantía de un crédito dinerario. (Artículo 1º).

Si bien esta ley lo considera Título Valor, sólo es tal desdesu incorporación en la nueva Ley de Títulos Valores №27287 de19 dejunio del 2000, queen el Título Único de la Sección Séptima del Libro Segundo o "de los Títulos Valores específicos" incorpora a estos títulos hipotecarios en su normatividad. Las disposiciones de ésta ley priman sobre la anterior, por razón de la temporalidad y de su especificidad, y así por ejemplo, en la Quinta Disposición Transitoria seestablecequeel Reglamento dictado por la Superintendencia con Resolución No838-97 defecha 28 denoviembre de 1997 seguirá vigente en todo aquello que no resulte incompatible con las disposiciones de la Sección Séptima, antes aludida; aunque ésta queda facultada a expedir nuevas disposiciones, dentro de los noventa días siguientes a la fecha de entrada en vigencia de la ley.

El Decreto Legislativo № 861, Ley del Mercado de Valores, en su decimoquinta disposición final, autoriza la emisión del "Certificado Hipotecario Negociable", con un contenido similar al antes reseñado.

2. Para constituirlase debeextender una escritura pública, en la quesesolicite al Registro Público laemisión del Títuloy seinsertela valuación del inmueble practicada por un perito inscrito en el Registro de Peritos Tasadores de la Superintendencia de Banca y Seguros, conforme a los criterios señal ados en la Resolución SBS 572-97 (artículo $4^{\circ}$ del Reglamento). 
3. La hipoteca seránecesariamentedeprimer rango y en caso queel endosatario fuera una empresa del Sistema Financiero tendrá garantía exclusiva del crédito, con preferencia frentea otros acreedores del propietario del predio afectado, a tal extremo que aún en el caso de insolvencia del deudor el bien gravado será separado de la masa concursal constituyendo una identidad independiente. (Artículo $5^{\circ}$ del Reglamento). Setratadeun privilegio bancario.

4. El título seexpedirá por el Registrador Público en formulario aprobado por la Superintendencia Nacional de Registros Públicos, (SUNARP) a petición expresa del propietario de un bien susceptible de ser gravado, por acto unilateral manifestado en escritura pública, después de haber constatado la inexistencia de cargas o gravámenese inscrito la hipoteca. El Título debe contener los datos que indica el artículo 241o. El monto del gravamen está constituido por el valor total del bien. (Artículo $240^{\circ}$ de la Ley de Títulos Valores y 11 del Reglamento). Por Resolución dela SUNARP №258-99 se aprobó el formulario correspondiente.

5. El Título es emitido a la orden del propietario del inmueble quesegrava, es de librenegociación mediante endoso y, en el acto de efectuarse el primer endoso debe señalarse en el mismo título el monto del crédito en cuya garantía seafecta, la fecha devencimiento, forma de pago, plazos, tasas de interés y las demás condiciones que se crea convenientes; con el endoso se transmite el crédito consignado en el título y la hipoteca que lo garantiza; En el acto de realizarseel primer endoso sedeberá consignar en el Título el crédito que garantiza y sus datos (monto, plazo o plazos e intereses), a partir del cual secalifica como título val or. Los endosos sucesivos transfieren ambos derechos: el crédito y la hipoteca, sin que el endosante asuma responsabilidad solidaria. (Artícul o 2420 de la Ley de Títulos Valores).

Sepuedeendosar en blanco, en procuración, en propiedad y en fideicomiso. A falta de indicación contraria se presume que es en propiedad. (A rtículo 130del Reglamento).

El endoso y negociación secundaria del Título es libre, salvo queseincluya cláusula prohibiendo su posterior negociación. (Artículo $8^{\circ}$ del Reglamento).

El artículo 47.1 de la Ley de Títulos Valores permite su transferencia en propiedad mediante endoso; y en el 47.2 su afectación en garantía; 
6. Los pagos deberán constar literalmente en el Título como prescribe el artículo 14 del Reglamento. En el caso de haberse pactado el pago del crédito en armadas o cuotas, la falta de pago de una o más de ellas faculta al tenedor a dar por vencidos todos los plazosy exigir el íntegro, efectuando el correspondienteprotesto o formal idad sustitutoria. El artículo 84이 dela Ley de Títulos Val ores faculta prescindir del protesto, siendo suficiente para ejercitar la acción que se haya vencido el plazo o resulte exigible la obligación según el texto del título.

7. El artículo 54 de la Ley de Títulos Valores autoriza que en esos títulos se pacte prescindir de la ejecución judicial y que la venta se realice en forma directa o extrajudicial. Protestado el Título por fal ta de pago del crédito u obtenida la formalidad sustitutoria, procede la venta directa del bien hipotecado, sin intervención deautoridad judicial, al mejor postor, siempre que el precio en que se enajene no sea inferior al $75 \%$ de la valorización señalada en el Título y la venta se confíe a una empresa del Sistema Financiero Nacional autorizada a operar comisiones de confianza o fideicomisos, distinta al ejecutante. La facultad de venta otorgada es irrevocable. Siempre el tenedor podrá recurrir al proceso de ejecución de garantías. (Artículos 243.1 y 243.2 de la Ley de Títulos Valores y 16 del Reglamento)

8. Si el producto de la venta del bien hipotecado no cubre el monto total del crédito garantizado, el Juez o la empresa facultada para la venta dejará constancia de ello en el Título, con cuyo mérito el tenedor tendrá acción cambiaria contra el primer endosante por el sal do resultante. Según anota el artículo $10^{\circ}$ del Reglamento losendosantes distintos al titular no asumen obligación.

9. En caso de venta directa el último tenedor del título y ejecutante dejará constancia de la venta realizada y el precio pagado, y otorgará la escritura pública a favor del adquiriente del predio, acompañando como anexo el original del Título protestado. (Artículo $17^{\circ}$ del Reglamento.)

La hipoteca sólo se levantará contra devolución del Título, debidamente cancelado por el último endosatario.

En caso deventa judicial o extrajudicial se cancelarán todos los gravámenes y carga inscritos con posterioridad a la hipoteca. 
10. En caso de demostrarsequeel Título seprotestó a pesar dehabersecumplido con los pagos, o se compl etó en forma contraria a los acuerdos, el afectado sólo podrá dirigir sus acciones contra la persona que actuó en su perjuicio, quien será sancionado con una multa equivalente al doble del valor del predio. (Artículo $20^{\circ}$ del Reglamento.)

11. En caso de perdida, extravío, sustracción, deterioro o cualquier afectación de la integridad del Título, el Registro Público podrá expedir uno nuevo, previaResolución Judicial expedida en proceso deineficacia detítulo valor señalado en el Código Procesal Civil (Artículo 21 del Reglamento.)

12. El propietario quehubiere pagado el título podrá devolverlo para solicitar la expedición de uno nuevo en reemplazo, manteniéndose la hipoteca.

13. El artículo $245^{\circ}$ de la Ley deTítulos Valores haceaplicables a estetítulo las disposiciones referidas a la letra de cambio, en cuanto no resulten incompatibles con su naturaleza. Así:

La forma y modalidades del endoso (125.2)

El vencimiento, en sus distintas modal idades: a la vista, meses o años;

El pago. En el lugar señalado (145)

El protesto. (147. La cláusula sin protesto)

14. Debe sal udarse la incorporación a nuestra legisl ación deesta nueva forma hipotecaria, aún cuando no ha logrado desvincularsedesus raíces romanas. Las diferencias con su antecedente doctrinal del derecho germano son saltantes.

No limita la responsabilidad al sólo inmueble hi potecado, pues en caso deque su precio de venta no cubra el crédito, hay acción cambiaria contra el primer endosante del título, o sea el propietario.

Quien ponga este título en circulación siempre responde del pago personalmente.

5. EL MERCADO

1. El M ercado. 2. El Mercado Secundario de Hipotecas. 
1. Bien está la teoría. En la práctica esto no ha tenido desarrollo, entiendo por falta de divulgación de la normatividad legal y la creación de una cultura relativa a un Mercado Secundario. Surgen una serie deinterrogantes: qué pasará cuando un ciudadano cualquiera, premunido de su Título Hipotecario se presente a una entidad financiera solicitando un crédito con esa garantía. Qué pasará cuando se presente ante un particular, interesado en invertir. Las entidades financieras deberán establecer un procedimiento interno que les permita verificar rápidamenteel instrumento quelepresenten.

En realidad tal Título es un papel más en el Mercado. Pero además es un papel novedoso, con una serie de atributos a los que no estamos acostumbrados, y que por lo mismo originarán si no desconfianzas, por lo menos interrogantes y dudas. Es necesario difundir su uso como un nuevo instrumento decrédito.

Por ejemplo, uno de estos aspectos novedosos es la venta directa del bien hipotecado por el acreedor. Esto es jurídicamente inobjetable. En realidad esa facultad corresponde al origen de la hipoteca. El acreedor hipotecario romano procedía directamenteala venta del bien hipotecado tal como podía vender a su deudor incumplido como esclavo para satisfacer su crédito. Entrenosotros hay varios antecedentes legislativos, como la Ley de Bancos de 2 deenero de 1889, y la ley de urbanizadoras de 14 denoviembre de 1900 quefacultaban la venta directa, sin formula dejuicio. El propio Código Civil vigente en su artículo 1069 permite la venta directa de la prenda por el acreedor prendario cuando su crédito no es satisfecho.

Me parece que éste papel necesita de mayores seguridades, que necesariamenteserelacionan con el mundo delos riegos y queen la economía moderna están cubiertos por los Seguros.

Para echar a andar éste papel, se necesita asegurar al inversionista, dos aspectos:

El primero esquela hipoteca estébien constituida. Por ahí andan los agentes de pleitos, prestos a interponer una acción penal, o una acción civil de nulidad, y por último una acción de amparo, de esas que abundan, y que seguramente no se acogerá, pero que cumplirá la finalidad de entorpecer. Esteriesgo secubrecon un seguro dehipoteca, o detítul os. El Decreto Supremo 
de fecha 15 de mayo de 1964 autorizó los seguros dehipoteca, destinadosa garantizar al acreedor hipotecario el cobro del capital adeudado, interesesy demás.

El segundo se refiere al pago. Las centrales de riesgos darán alguna información sobreel deudor. Esa información puedeser buena, pero el riesgo existe para el caso de fallecimiento. Entonces será necesario un Seguro de Vida sobresaldo deudor. LaLey 16168 instituyólibredeimpuestosel seguro de vida sobresaldo deudor.

Estos dos seguros van a encarecer el negocio; pero le darán seguridad. Una vez colocado el Título, puede ser transferido, trasladándose el tema a un mercado Secundario.

\section{El Mercado Secundario de Hipotecas}

Un mercado se define como el conjunto de operaciones comerciales que afectan un determinado sector de bienes. Es así mismo el conjunto de consumidores capaces de adquirir un producto. Y es también el estado de evolución de la oferta y de la demanda de determinado sector de bienes.

El mercado primario dehipotecas está constituido por todas las actividades dirigidas a lograr la colocación de créditos hipotecarios, y desde luego las personas y empresas que participan en la oferta y demanda de dichos créditos.

El mercado secundario está formado por la oferta y demanda realizadas por las personas y empresas interesadas en lograr la transferencia de créditos hipotecarios, o del valor monetario delosmismos, como títulos de inversión.

El mercado primario está dirigido a satisfacer la demanda de préstamos hipotecarios. El mercado secundario en cambio cumple dos funciones distintas:

Permiteemplear los créditos hipotecarios o el val or monetario delos mismos, con el propósito de anticipar la recuperación de los capitales invertidos en el mercado primario, el que puede utilizarse en el otorgami ento denuevos créditos. Produce una multiplicación de los recursos. 
Constituye un sistema que permite transferir los créditos hipotecarios o el valor monetario de los mismos a favor de terceras personas, mediante la emisión deun instrumento deinversión atractivo para quienes no participen en el mercado primario.

Cada mercado secundario puede al canzar características determinadas, según la orientación que se le quiera dar.

La creación de un mercado secundario de hipotecas en el Perú es un proyecto antiguo. Se inicia con la creación y desarrollo del Sistema de A horro y Préstamo para Vivienda, integrado por las M utuales deVivienda (Ley 12813) y su organismo central El Banco de la Vivienda del Perú (Ley 14241). Las colocaciones en préstamos hipotecarios a largo plazo utilizando para ello mayormente depósitos de ahorro a la vista, generaba en determinados momentos problemas deliquidez, y la cesión de las hipotecas a favor del Banco de la Vivienda, era sólo un paliativo, pues dicho Banco estatal tampoco disponía detodo el capital necesario como para asumir la cartera. ${ }^{36}$

Entonces su propuso y sugirió la creación de un M ercado Secundario, que permitiera a las Mutuales anticipar la recuperación desuscréditos, mediante la cesión de sus créditos a largo plazo a inversionistas, para lo cual era necesario ofrecerles seguridad y rentabilidad.

Son numerosos los estudios que se realizaron y los proyectos que se presentaron. Entre otros los real izados por el Instituto Jurídico de la Unión Interamericana deA horroy Préstamo para Vivienda, y la Tesis delos doctores Alberto León Viacroze y Ernesto Roca Bussalleau, del año 1974.37

Treinta años después, recién se dieron los instrumentos legales necesarios para la creación y funcionamiento de un Mercado Secundario, pero aún esta pendiente su difusión. 
Manuel Sánchez-Palacios Paiva - El Título de crédito hipotecario negociable

${ }^{24}$ León J. Consolidación del Sistema de Títulos H ipotecarios. Instituto Peruano de Economía.

25 Serafini F. Derecho Romano, , $9^{\circ}$ Edición, Barcelona Tomo I pag. 477

26 Derecho Hipotecario. Ignacio de Casso, Madrid 1951, pag. 588.

27 Exposición de Motivos Oficial del Código Civil, Hipoteca, Jack Bigio, Lima 1998, Pág.36.

28 Ibídem pag. 37

${ }^{29}$ Koch A. El Crédito en el Derecho. Madrid 1946, pag 107.

30 Biggio J., Lima, 1998, pag. 80.

31 Brunner H. Historia del Derecho Germánico. 8 Edición, Barcelona 1936, pag. 197.

32 Lacruz Berdejo J. Lecciones de Derecho Inmobiliario Registral,. Zaragoza 1957, pag. 33.

33 DeCasso I. Derecho Hipotecario, obra citada, pag. 700

${ }^{34}$ Kipp y Wolff. Tratado de Derecho Civil, Ennecerus, Traducción de la 32 edición alemana. Barcelona 1936, Tomo III, Derecho de Cosas, Volumen $1^{\circ}$, pag. 196y ss.

35 Von Tuhr A. Derecho Civil. Teoría General del Derecho Civil Alemán. Buenos A ires 1948. Volumen III 1 pag. 120.

36 A nales dela Primera Convención de Instituto Jurídico dela Unión Interamericana deA horro y Préstamo para la Vivienda, 1978. Unión Interamericana de A horro y Préstamo para Vivienda.

37 León V.J. y Roca B. E. Mercado Secundario de Créditos Hipotecarios, publicado por la Cámara Peruana de A sociaciones deA horro y Prestamo para Vivienda, Lima. 1974. 